\title{
Hyperprolactinemia-inducing antipsychotics increase breast cancer risk by activating JAK-STAT5 in precancerous lesions
}

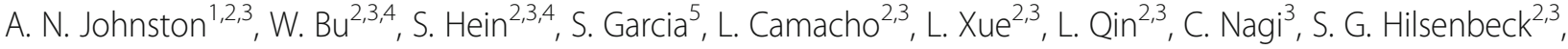 \\ J. Kapali ${ }^{2}$ K. Podsypanina ${ }^{6,7}$, J. Nangia ${ }^{3}$ and Y. Li $i^{1,2,3,4,8^{*}}$
}

\begin{abstract}
Background: Psychiatric medications are widely prescribed in the USA. Many antipsychotics cause serum hyperprolactinemia as an adverse side effect; prolactin-Janus kinase 2 (JAK2)-signal transducer and activator of transcription 5 (STAT5) signaling both induces cell differentiation and suppresses apoptosis. It is controversial whether these antipsychotics increase breast cancer risk.
\end{abstract}

Methods: We investigated the impact of several antipsychotics on mammary tumorigenesis initiated by retrovirusmediated delivery of either ErbB2 or HRas or by transgenic expression of Wnt-1.

Results: We found that the two hyperprolactinemia-inducing antipsychotics, risperidone and pimozide, prompted precancerous lesions to progress to cancer while aripiprazole, which did not cause hyperprolactinemia, did not. We observed that risperidone and pimozide (but not aripiprazole) caused precancerous cells to activate STAT5 and suppress apoptosis while exerting no impact on proliferation. Importantly, we demonstrated that these effects of antipsychotics on early lesions required the STATS gene function. Furthermore, we showed that only two-week treatment of mice with ruxolitinib, a JAK1/2 inhibitor, blocked STAT5 activation, restored apoptosis, and prevented early lesion progression.

Conclusions: Hyperprolactinemia-inducing antipsychotics instigate precancerous cells to progress to cancer via JAK/STAT5 to suppress the apoptosis anticancer barrier, and these cancer-promoting effects can be prevented by prophylactic anti-JAK/STAT5 treatment. This preclinical work exposes a potential breast cancer risk from hyperprolactinemia-inducing antipsychotics in certain patients and suggests a chemoprevention regime that is relatively easy to implement compared to the standard 5-year anti-estrogenic treatment in women who have or likely have already developed precancerous lesions while also requiring hyperprolactinemia-inducing antipsychotics.

Keywords: Cancer, Breast cancer, Antipsychotics, Neuroleptics, Prolactin, STAT5, JAK, Ruxolitinib, Mammary gland

\section{Background}

Psychiatric medications are among the top five drugs in sales in the USA [1]. Both typical (class 1) and atypical (class 2) antipsychotics (also known as neuroleptics) act by antagonizing dopamine and thus blocking postsynaptic dopamine D2 receptors in the pituitary gland; atypical antipsychotics additionally suppress serotonin

\footnotetext{
* Correspondence: liyi@bcm.edu

${ }^{1}$ Translational Biology and Molecular Medicine, Baylor College of Medicine, Houston, TX 77030, USA

${ }^{2}$ Lester and Sue Smith Breast Center, Baylor College of Medicine, Baylor College of Medicine, Houston, TX 77030, USA

Full list of author information is available at the end of the article
}

receptors [2]. Dopaminergic receptors typically suppress prolactin (PRL) production and secretion; thus, a multitude of antipsychotics are associated with elevated serum PRL [2]. A retrospective study of 422 psychiatric patients found that antipsychotic therapy was strongly associated with hyperprolactinemia [3], and that serum PRL levels were affected in a dose-dependent manner [4-6].

PRL binds to its receptor PRLR to activate Janus kinase 2 (JAK2). JAK2 then phosphorylates and activates the signal transducer and activator of transcription 5 (STAT5). Once phosphorylated, STAT5 forms homodimers or heterodimerizes with another STAT family

(C) The Author(s). 2018 Open Access This article is distributed under the terms of the Creative Commons Attribution 4.0 International License (http://creativecommons.org/licenses/by/4.0/), which permits unrestricted use, distribution, and 
member, translocates to the nucleus, and transactivates its targets, which regulate alveolar differentiation and milk production and proliferation and apoptosis [7]. PRL-JAK2-STAT5 signaling is highly activated during late pregnancy and lactation, and is required for alveolar expansion and milk production [7]. Transgenic or retrovirus-mediated expression of constitutively activated STAT5 in normal mammary epithelia in nulliparous mice causes alveolar differentiation and milk production $[8,9]$. Hyperprolactinemia associated with the use of antipsychotics of both classes often causes mammary swelling and lactation that are not associated with pregnancy [10]. Mammary cell differentiation caused by PRL-PRLR-JAK2-STAT5 signaling is a mechanism by which an early-age pregnancy reduces breast cancer risk [11]. However, we have also reported that STAT5 activation in preexistent precancerous lesions in mice instigates accelerated progression to cancer via suppression of the apoptosis anticancer barrier [11]. This finding provides an explanation for increased breast cancer risk associated with a late-age pregnancy when early lesions may have already formed. Activated forms of JAK2 and STAT5 have been reported in human early breast lesions and cancer [7, 12-16] and in other human cancers $[7,17]$.

While it explains the dichotomous effects of early versus late-age pregnancy on breast cancer risk, the dualrole of PRL-JAK2-STAT5 in both promoting normal cell differentiation and suppressing the anticancer barrier in precancerous cells also predicts that hyperprolactinemiainducing antipsychotics may have a similar dichotomous impact on breast tumorigenesis - reducing breast cancer risk when taken at a young age but increasing breast cancer risk if started at an older age or when early lesions have already been diagnosed. However, when started at an early age, this type of medication is usually taken for decades or for lifetime [18], likely leading to protection against breast cancer earlier on but increased risk later in life. Therefore, epidemiological studies of breast cancer risk in patients on antipsychotics must consider hyperprolactinemia, starting age and length of treatment, precancerous lesion status, and multiple other confounding factors such as obesity and poor health status [2, 19-23]. The limited work in this area has not stratified patients to consider all of these variables. Not surprisingly, these studies have resulted in inconclusive or contradictory reports [19, 24-31], although a few studies have detected a significant increase in breast cancer in women who were prescribed dopamine antagonists compared to age-matched controls who were not prescribed antipsychotics [32, 33]. Data from well-controlled laboratory studies may provide the experimental foundation for sophisticated epidemiological studies that will involve multiple patient registries and are stringently controlled. Importantly, laboratory studies may especially expose potential cancer risk of administering hyperprolactinemia-inducing antipsychotics in patients who may have already developed precancerous lesions. However, there have been no significant laboratory studies to investigate the influence of antipsychotics on breast cancer risk. Here, we report that in mouse models that closely mimic human breast cancer initiation, hyperprolactinemia-inducing antipsychotics accelerate early lesion progression to cancer via activation of JAK-STAT5 signaling to suppress the apoptosis anticancer barrier. These findings highlight the potential risk associated with the use of hyperprolactinemiainducing antipsychotics in women at risk of breast cancer and urgently calls for epidemiological studies specifically designed to examine breast cancer risk in women who have already developed precancerous lesions while also requiring hyperprolactinemia-inducing antipsychotics.

\section{Methods \\ Experimental animals}

The mouse mammary tumour virus promoter (MMTVtva) (MA line) and STAT5 $\mathrm{a}^{-/-}$mice used in this study are on a Friend virus B (FVB) genetic background and have been previously reported [34, 35]. Briefly, lesion initiation is achieved by intraductal injection of a Rous sarcoma virus-based vector - replication-competent avian sarcoma (RCAS) - to deliver an oncogene into a minute subset of mammary epithelial cells in an otherwise normally developed mammary gland [34]. This allows cancer to initiate in a "field" of normal mammary cells in a normal mammary gland as human breast cancer usually initiates and evolves [34]. This subset of mammary epithelial cells was made susceptible to RCAS infection by transgenic expression of the gene encoding the RCAS receptor TVA from the MMTV promoter (MMTV-tva) [34]. STAT5a ${ }^{-1-}$ mice have been previously described [35]; the STAT5a knockout mice on the FVB background have normal mammary development unlike those on the 129 background [11, 35]. All animals were handled according to the animal protocol approved by Baylor College of Medicine (BCM) Institutional Animal Care and Use Committee (IACUC).

\section{Early lesion and tumor studies}

RCAS virus was prepared as previously described $[34,36]$ and was intraductally injected into MMTV-tva mice at 10 weeks of age. Five days later they were randomized and treated with either a drug or diluent for 2 weeks (early lesion studies) or until euthanasia (tumor study). Mice in the tumor latency study were palpated thrice weekly and tumor size was recorded. When tumors reached $2.0 \mathrm{~cm}$ in diameter, cumulatively, the mice were euthanized. Tumor-free mice were euthanized 12 months post injection. 


\section{Drug treatments}

Pimozide (cat. no. P1793; Sigma-Aldrich) was intraperitoneally (IP) administered daily at $5 \mathrm{mg} / \mathrm{kg}$. Risperidone (cat. no. 1604654; Sigma-Aldrich) was delivered IP daily (3 $\mathrm{mg} / \mathrm{kg}$ ) for 2 weeks (early lesion study) or in drinking water $(1.56 \mathrm{mg} / \mathrm{l})$ until euthanasia (tumor latency study), resulting in the same daily dose based on the calculation previously reported [37]. Aripiprazole (cat. no. SML0935; Sigma-Aldrich) was delivered via IP injection in a daily dose of $3 \mathrm{mg} / \mathrm{kg}$ for 2 weeks, and clomipramine (cat. no. 1140247; Sigma-Aldrich) was delivered in drinking water (190 mg/l), resulting in a daily dose of $28 \mathrm{mg} / \mathrm{kg}$. All drugs were diluted in dimethyl sulfoxide (DMSO) to the appropriate concentrations. Both ruxolitinib and control chow was provided by Incyte Corp. Ruxolitinib chow was packaged in a pre-determined measurement of $2000 \mathrm{mg} / \mathrm{kg}$ chow; mice were allowed to free-feed for the duration of the study.

\section{Serum PRL}

Serum PRL was determined using the Sigma-Aldrich Mouse Prolactin ELISA kit (RAB0408) using the manufacturer's protocol.

\section{Immunostaining and microscopy}

Immunohistochemistry analysis (IHC) and immunofluorescence (IF) were performed as previously described $[9,11,34]$. MOM and vectastain Elite $A B C$ rabbit kits (cat.no. PK-2200 and PK-6101; Vector Laboratories) were used according to the manufacturer's protocols. Primary antibodies used included mouse monoclonal antibodies against HA (1:250; cat.no.901503; Covance) and BCL-xL (1:50; cat.no. K1308; Santa Cruz) and rabbit antibodies against pSTAT5 1:300; cat.no. 9359 L; Cell Signaling), cleaved caspase 3 (1:300; cat.no. Asp175; Cell Signaling), and Ki67 (1:300; cat.no. MIB-1; Lycra). Secondary antibodies for IF were Alexa Fluor 568 goat-antirabbit, and Alexa 488 goat-anti-mouse. Nuclei were counterstained with 4'-6-diamidino-2-phenylindole (DAPI)-containing mounting medium and hematoxylin, respectively, for IF and IHC. TUNEL assay was performed using the ApopTag Red in situ TUNEL detection Kit (Chemicon, S7165). Bright-field images were captured using a Leica DMLB microscope. IF images were captured using the Zeiss Axiskop2 plus microscope.

\section{Quantification of stained sections}

For quantification of cells stained for a marker, 10 random fields of early lesions in each mammary gland were captured, and both positively stained cells and the total number of cells in the lesion as identified by DAPI or hematoxylin staining were counted to determine the percentage of positivity. Image software was used for counting cells and determining lesion size. The total numbers of cells in IF images were counted using a semi-automotive program that has been previously described [38]. Fixed thresholds were set to analyze both experimental and control mammary glands.

\section{Lung metastasis study}

Lung metastases were detected by the quantitative-PCR (qPCR) method using a set of primers specific for the RCAS provirus (CTTCCCTGCCGCTTCC; FWD: AGCCGCCTCAAGTCATGATG; GCTCTTTCCAATGTACCGATAACCT). DNA was extracted from the largest, left-most lobe of the lung. A mammary tumor induced by RCAS-caErbB2 was used as positive control, and a lung from a FVB mouse without virus injection was used as negative control. The relative amounts of the RCAS provirus with respect to the endogenous gene $\beta$-actin were determined using the 7500 Fast System software provided by Applied Biosystems.

\section{Statistical analysis}

All numbers in this study are reported as medians and interquartile ranges in the format median (IQR). Statistical analyses of quantification of stained sections were performed using analysis of variance (ANOVA) or the Mann-Whitney test. In cases where data were distributed normally, Student's $t$ test for independent samples with Holm's correction for multiple comparisons was used. Tumor-free survival analysis was performed using the generalized Gehan-Wilcoxon test with Rho =1, and Kaplan-Meier survival curves. All tumor-free survival analyses were performed in $\mathrm{R}$ with the survival package using $\mathrm{R}$ commander interface. All other graphs were generated using Prism software. Each dot in the dot plots generated for this study represents one mouse.

\section{Results}

Treatment with hyperprolactinemia-inducing antipsychotics accelerates tumorigenesis from breast cancer cells with an oncogenic mutation

We have reported a mouse model that closely mimics human breast cancer initiation and is ideally suited for studying hormones and other factors that may impact breast cancer risk $[9,11,34,38-42]$. Tumor initiation is achieved by intraductal injection of a Rous sarcoma virus-based vector, RCAS, to deliver an oncogene into a small subset of mammary epithelial cells $(<0.3 \%$ of the mammary gland) in a normally developed mammary gland so that cancer initiates in a "field" of normal mammary cells in a normal mammary gland as most human breast cancers initiate and evolve [34]. This subset of mammary epithelial cells was made susceptible to RCAS infection by transgenic expression of the gene encoding the RCAS receptor TVA from the MMTV promoter (MMTV-tva) [34]. The transgenic avian tva is only 
required for the initial virus infection; the virus does not replicate in mammalian cells. Additionally, the oncogene is transcriptionally controlled by the proviral RCAS long terminal repeat (LTR); it is constitutively active and is not influenced by the presence of reproductive hormones such as prolactin $[39,43]$. Using this method, we explored the effect of several antipsychotics on mammary cancer development from preexisting early lesions. We injected 10 week-old MMTV-tva mice intraductally with RCAS-caErbB2 to infect approximately $0.3 \%$ of the luminal epithelial cells [34, 44]. RCAS-caErbB2 expresses a constitutively active form of rat ErbB2 (HER2/ $\mathrm{Neu}$ ); $\mathrm{ErbB2}$ is amplified/mutated in $20-25 \%$ of human breast cancers [45]. Five days following injection, mice were randomized for treatment with risperidone $(3 \mathrm{mg} /$ kg daily), a commonly prescribed class 2 , "atypical" antipsychotic that is known to cause hyperprolactinemia [2], or with vehicle. Introduction of the oncogene took place before drug treatment so as to specifically investigate antipsychotic effects on preexisting precancerous early lesions rather than the overall risk that antipsychotics may pose on the normal mammary epithelia. Mice were continually treated with either risperidone or the diluent control in drinking water for the duration of the study. While vehicle-treated mice developed tumors with a median latency of 112 days, the risperidone cohort developed tumors with a median latency of only 59 days ( $p=0.000138$; Fig. 1a). Additionally, the risperidonetreated cohort had a greater tumor multiplicity than the control $(p=0.002$; Fig. 1b). When the tumor size reached $2.0 \mathrm{~cm}$ in diameter, mice were euthanized. As expected, serum PRL levels were significantly increased in the risperidone cohort ( $p=0.004$; Fig. $1 \mathrm{c})$. Tumors from both cohorts were high-grade, poorly differentiated, and highly mitotic with areas of necrosis. Many of the tumor cells were highly pleomorphic with large nuclei, often with metaplastic features. These tumors extensively invaded the surrounding fibroadipose tissue, skeletal muscle, and nerves (Additional file 1: Figure S1A). Likewise, incidence of pulmonary metastasis was
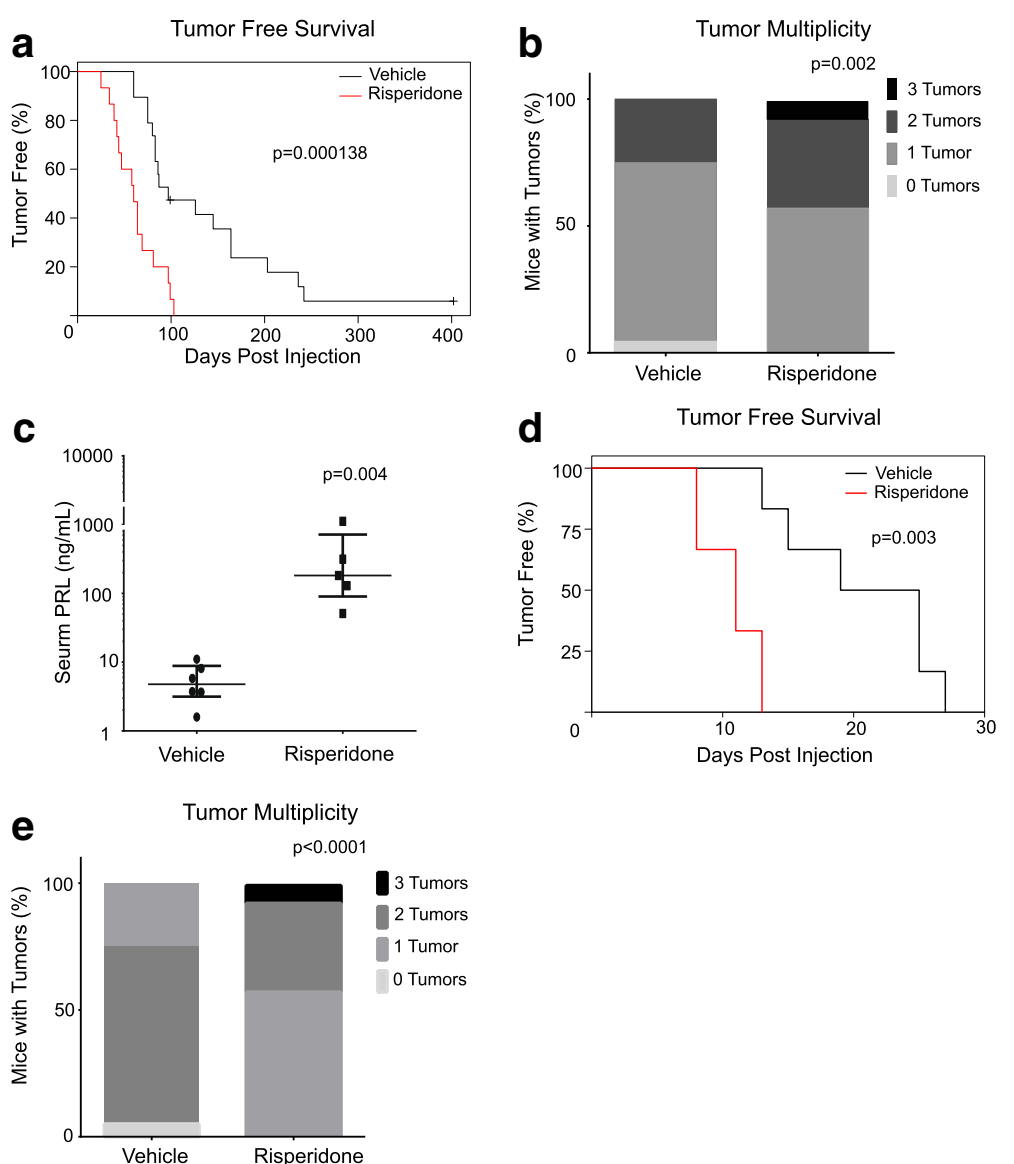

Fig. 1 Risperidone promotes carcinogenesis initiated by caErbB2 and HrasQ61L. a Kaplan-Meier tumor-free survival curve of mice infected by replication-competent avian sarcoma (RCAS)-caErbB2. The $p$ value was determined by the generalized Gehan-Wilcoxon test with Rho $=1$. b Tumor multiplicity. The chi square test was for used comparison. c Serum prolactin (PRL) levels. The Mann-Whitney test was used to determine the $p$ values. Each dot in this plot represents one mouse. $\mathbf{d}$ Kaplan-Meier tumor-free survival curve of mice infected by RCAS-HRasQ61L. The $p$ value was determined by the generalized Gehan-Wilcoxon test with Rho $=1$. e Tumor multiplicity. The chi square test was for used comparison 
similar in the two cohorts of mice based on qPCR analysis of the RCAS-proviral load ( $p=0.753$; Additional file 1: Figure S1B). Therefore, we conclude that treatment with risperidone accelerates tumorigenesis and increases tumor multiplicity in mice with preexisting precancerous mammary lesions, while not influencing the grade, aggressiveness, or metastatic potential of the resulting tumors.

To investigate whether risperidone also accelerated tumorigenesis initiated by other oncogenic events, we injected MMTV-tva mice $(\mathrm{n}=25)$, at 10 weeks of age, with RCAS carrying an activated form of HRas, HRasQ61L (RCAS-HRasQ61L). RAS genes are known to be amplified/overexpressed/mutated in a subset of human breast cancer, and their protein products often activated [46-49]. Five days following injection, mice were continually treated with risperidone or vehicle in their drinking water. While vehicle-treated mice developed tumors with a median latency of 25 days, the risperidone cohort developed tumors with a median latency of only 11 days ( $p=0.003$; Fig. 1d). Additionally, the risperidone-treated cohort had a higher tumor multiplicity than the control $(p<0.0001$; Fig. 1e). Taken together, these data suggest that risperidone stimulates tumorigenesis initiated by multiple oncogenic events.

We next determined if this tumorigenic acceleration was due to antipsychotic effects on early lesion development. Here we used RCAS-caErbB2-infected mice and treated them with risperidone or vehicle for only 2 weeks. Early lesions were defined as any hyperplastic ductal foci comprised of three or more layers of epithelial cells stained positively for the provirus-encoded oncogene product HA tag. Risperidone-treated mice had more early lesions and higher early lesion burden than the vehicle control cohort (Fig. 2a). Therefore, we conclude that risperidone promotes early lesion progression.

To test whether the above-observed risperidone effect on mammary early lesions is broadly applicable across
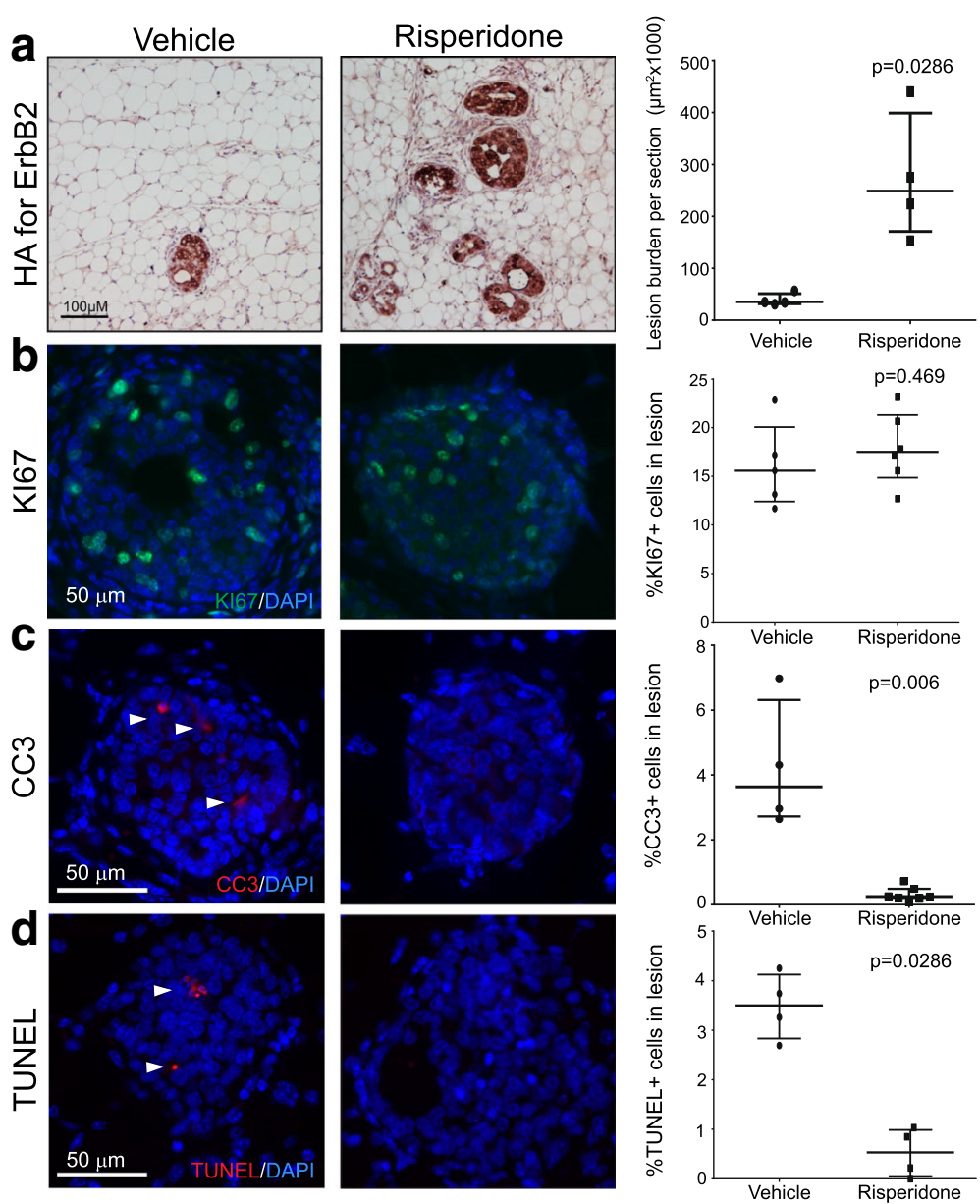

Fig. 2 Risperidone increases early lesion burden and lowers the level of apoptosis. a Immunohistochemistry analysis and the accompanying dot plot for the HA tag on replication-competent avian sarcoma (RCAS)-caErbB2 provirus. b Immunofluorescence for Ki67 and the accompanying dot plot. $\mathbf{c}$ and $\mathbf{d}$ Immunofluorescence staining for cleaved caspase 3 (c) and TUNEL assay (d) with the accompanying dot plots. The $p$ values were determined by the Mann-Whitney test. Each dot in these plots represents one mouse 
different subtypes of breast cancer, we administered risperidone or vehicle to mice transgenic for MMTV-Wnt1 [50], which develops basal-like tumors and some estrogen receptor (ER)-positive tumors [51-53]. Mice treated with risperidone for 2 weeks developed extensive ductal branching and many more and larger early lesions compared to vehicle-treated mice (Additional file 2: Figure S2A-2B). Taken together, these data suggest that risperidone stimulates the progression of early lesions that are the precursor to multiple breast cancer subtypes.

To determine the underlying mechanisms by which risperidone spurred early lesion expansion, we first compared the precancerous cell proliferation in these two cohorts of mice injected with RCAS-caErbB2. Ki67 staining detected approximately $20 \%$ of positive cells in both sets of early lesions ( $p=0.469$; Fig. $2 \mathrm{~b}$ ), suggesting that proliferation did not play a significant role in risperidone acceleration of early lesion development. Besides cell proliferation, evasion of apoptosis serves a key role in the progression of precancerous early lesions to cancer $[54,55]$. We have reported that apoptosis was rapidly activated in mammary cells following ErbB2 activation to provide a barrier to cancer [11, 42, 44]. Both cleaved caspase 3 (CC3) and TUNEL detected robust apoptosis (3.6\% (2.7-6.3\%) and $3.5 \%(2.8-4.1 \%)$, respectively) in early lesions in vehicle-treated mice, as expected; however, these apoptosis levels were diminished in the risperidone cohort $(0.2 \%(0.07-0.5 \%), p=0.006$ and $0.5 \%$ (0.05-0.9\%), $p=0.0286$, respectively) (Fig. 2c-d). These results demonstrate that treatment with risperidone allows precancerous cells to suppress the apoptotic anticancer barrier to increase early lesion burden.

To test whether other hyperprolactinemia-inducing antipsychotics also instigate early lesion progression, we treated a separate cohort of early lesion-bearing mice with pimozide, which is a "typical", class 1 antipsychotic that is also known to induce hyperprolactinemia [10]. As expected, this antipsychotic also led to hyperprolactinemia in these mice ( $p=0.007$; Additional file 3: Figure S3A). Like risperidone, pimozide ( $5 \mathrm{mg} / \mathrm{kg}$ daily) for 2 weeks increased early lesion numbers (from $22(12.8-31)$ to 64 (42.5-98), $p=0.004$ ) and led to a greater early lesion burden (Additional file 4: Figure S4A). While not affecting cell proliferation (Additional file 4: Figure S4B), pimozide suppressed apoptosis in early lesions based on both CC3 and TUNEL $(p=0.0002$ and $p=0.0007$, respectively; Additional file 4: Figure S4C-3D). Taken together, these data indicate that hyperprolactinemia-inducing antipsychotics dismantle the apoptosis anticancer barrier in early lesions and instigate their progression to cancer.

To investigate whether antipsychotics that do not cause hyperprolactinemia have the potential to accelerate early lesion progression, we tested aripiprazole, a widely prescribed class 2, "atypical" antipsychotic that does not elevate prolactin levels but is otherwise mechanistically similar to risperidone [2]. Two weeks of aripiprazole $(28 \mathrm{mg} / \mathrm{kg}$ daily) did not elevate serum prolactin levels (Additional file 5: Figure S5A), and failed to increase the load of RCAS-caErbB2-initiated early lesions (Additional file 5: Figure S5B). Likewise, this drug did not affect cell proliferation (Additional file 5: Figure $\mathrm{S} 5 \mathrm{C}$ ) or apoptosis as tested by TUNEL (Additional file 5: Figure S5D). In addition, clomipramine, a commonly prescribed antidepressant that did not cause hyperprolactinemia in our mouse model $(p=0.151$; Additional file 5: Figure S5E) also failed to increase early lesion burden ( $p=0.687$; Additional file 5: Figure S5F). Together, we conclude that hyperprolactinemia-inducing antipsychotics cause preexisting early lesion to suppress the apoptosis anticancer barrier and to accelerate progression to cancer; these cancer-promoting effects are associated with hyperprolactinemia.

\section{Hyperprolactinemia-inducing antipsychotics activate STAT5}

PRL is a key hormone released during pregnancy and lactation, and activates STAT5 via its receptor PRLR and the receptor-associated JAK2 [7]. Forced or pregnancyassociated JAK2/STAT5 activation lowers the apoptosis anticancer barrier in preexisting early lesions and advances the progression to cancer [11]. To understand the underlying mechanism by which hyperprolactinemiainducing antipsychotics suppress the apoptosis anticancer barrier and increase breast cancer risk, we asked whether treatment with risperidone activates the STAT5 signaling pathway. In vehicle-treated mice bearing early lesions initiated by RCAS-caErbB2, pSTAT5 + cells were detected in $11 \%(5.7-30.3 \%)$ of precancerous cells, a level similar to those previously reported [11]; however, 2 weeks of risperidone treatment increased their population size to $86.4 \%$ $(84.2-94.3 \%)(p=0.0079$; Fig. 3a). Induction of STAT5 activity was also detected in normal ducts that did not gain caErbB2 (Fig. 3a). We confirmed that serum PRL levels were significantly increased in the risperidone cohort ( $p=0.029$; Fig. $3 c) . B c l-x L$ and $\beta$-casein are genes that are transactivated by STAT5, and their gene products contribute to cell survival and alveolar differentiation, respectively $[56,57]$. As expected, $\beta$-casein was induced in early lesions and in normal ducts (Fig. 3b). Likewise, Bcl$\mathrm{xL}$ was induced in early lesions (Fig. 3d). Additionally, we found that pSTAT5 levels were elevated in lesions of the risperidone-treated MMTV-Wnt1 transgenic mice compared to the vehicle-treated control cohort (Additional file 2: Figure S2C).

Next, we tested whether pSTAT5 and its transcriptional target $\beta$-casein were also upregulated by pimozide. While $7.3 \%(3.4-14.6 \%)$ of cells in the early lesions of vehicle-treated mice were pSTAT5+, 58\% (50-89\%) of 

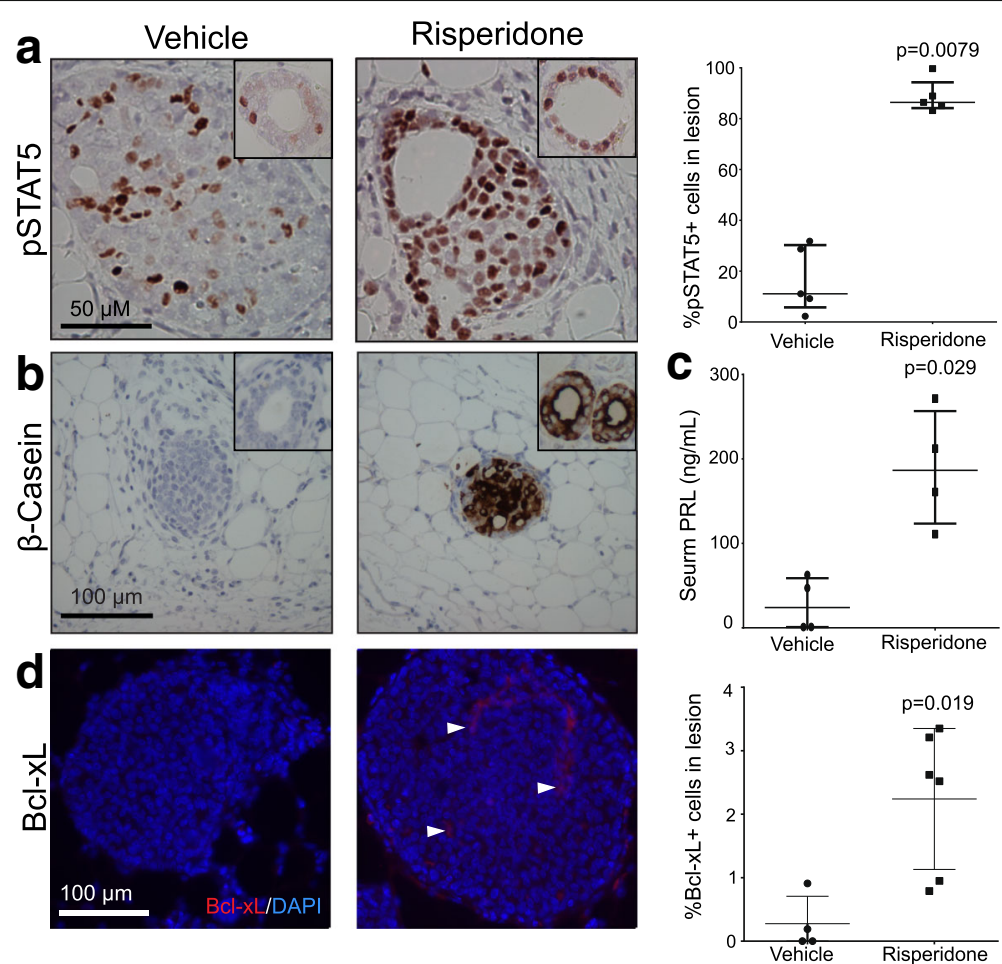

Fig. 3 Risperidone treatment increases signal transducer and activator of transcription 5 (STAT5) activity. a Immunohistochemistry staining for pSTAT5 in early precancerous lesions and in normal ducts (inset) and the accompany dot plot. $\mathbf{b}$ Immunohistochemistry analysis of the downstream effector of STAT5, $\beta$-casein, in early lesions and normal ducts (inset). c Serum prolactin (PRL) levels. $\mathbf{d}$ Immunofluorescence and the accompanying dot plot for $\mathrm{BCl}-\mathrm{xL}$. The $p$ values were determined by the Mann-Whitney test. Each dot in these plots represents one mouse

cells in the early lesions of pimozide-treated mice were pSTAT5+ $(p=0.0007$; Additional file 3: Figure $\mathrm{S} 3 \mathrm{~B})$. $\beta$-casein was also induced following pimozide administration (Additional file 3: Figure S3C). Of note, pimozide has been reported to block STAT5 activation in cultured cells [58, 59], but this potential direct effect on STAT5 was overridden in vivo by hyperprolactinemia-induced PRL signaling. To further test the association between hyperprolactinemia and activation of STAT5, we also stained for pSTAT5 in early lesions in mice treated with aripiprazole, which did not increase PRL. No evidence of STAT5 activation was detected (Additional file 3: Figure S3D). Together, these data suggest that hyperprolactinemiainducing antipsychotics activate STAT5 and its transcriptional targets to suppress the apoptosisanticancer barrier in preexisting precancerous cells, while simultaneously inducing alveolar differentiation in both early lesions and normal ducts.

\section{STAT5a is required for antipsychotic promotion of mammary tumorigenesis}

PRL-PRLR signaling activates STAT5 and possibly several other pathways including extracellular signal-related kinase (Erk) and protein kinase B (Akt) [60]. We tested whether the gene encoding STAT5a, the predominant form of STAT5 in the mammary gland and tumorigenesis [35, 61], is required for the above-observed effects of risperidone on early lesion progression, to investigate whether STAT5 activation is the crucial factor mediating antipsychotic stimulation of carcinogenesis. We utilized $S T A T 5 a^{-1-}$ mice on the FVB background as STAT5a ablation on this background does not significantly impair normal mammary development and lactogenesis [11]. These STAT5a knockout mice were bred to MMTV-tva mice, infected with RCAS-caErBb2, and 5 days later, continually treated with either risperidone or vehicle control for 2 weeks. STAT5 $a^{+/+} / \mathrm{MMTV}$-tva mice infected with RCAS-caErbB2 were also treated with risperidone for 2 weeks for comparison. Risperidone treatment failed to activate STAT5 in STAT5 $a^{-/-}$mice - the percentage of pSTAT5+ cells was comparable to that in the vehicletreated mice $(p=0.908)$ and much lower than that in STAT5 $a$ wild-type mice treated with risperidone $(p=0$. 004; Fig. 4a). The residual levels of pSTAT5 in STAT5 $a^{-1-}$ mice were likely due to the minor player pSTAT5b. Additionally, $\beta$-casein, a transcriptional target of STAT5, 

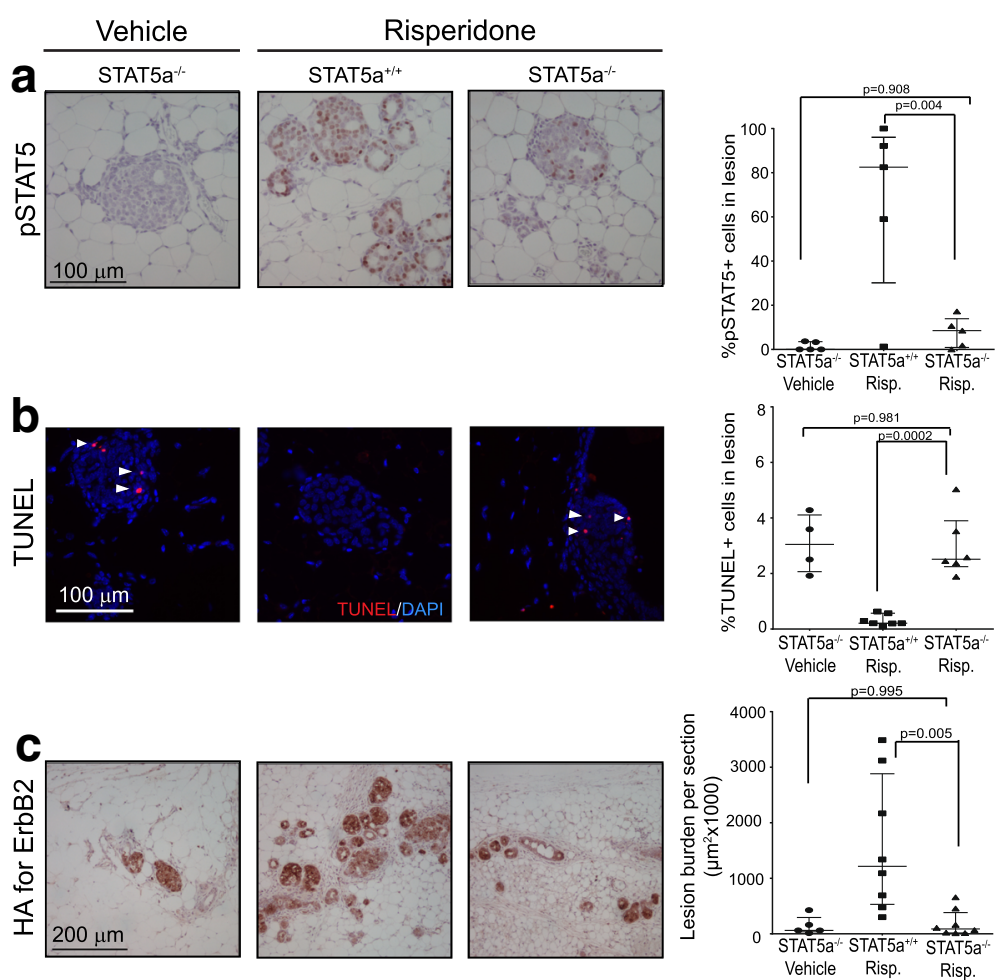

Fig. 4 Genetic ablation of signal transducer and activator of transcription 5 (STAT5) a dismantles the effects of risperidone on early lesions. a pSTAT5 immunohistochemistry analysis and the accompanying dot plot. $\mathbf{b}$ TUNEL assay and the accompanying dot plot. $\mathbf{c}$ Immunohistochemistry analysis and the accompanying dot plot for the HA tag on replication-competent avian sarcoma (RCAS)-caErbB2 provirus. The $p$ values were determined by analysis of variance. Each dot in these plots represents one mouse

was elevated in the risperidone-treated STAT5a wild-type mice, but severely diminished in the STAT5a knockout risperidone-treated group (Additional file 6: Figure S6). Next, we asked if STAT5a-knockout-induced diminishment of STAT5 activity restored apoptosis in early lesions in the risperidone cohort. In comparison to the wild-type mice treated with risperidone, the STAT5 $a^{-/-}$mice treated with risperidone had significantly elevated levels of apoptosis as measured by TUNEL ( $p=0.0002$; Fig. $4 \mathrm{~b})$, which were comparable to those in the vehicle-treated $\operatorname{STAT5}^{-/-}$mice $(p=0.981$; Fig. 4b). This finding indicates that STAT5a plays a pivotal role in the effects of risperidone on evading the apoptotic anticancer barrier. Next, we examined whether STAT5 activity reduction also led to a lower early lesion burden in risperidone-treated mice. Indeed, STAT5 $a^{-1-}$ mice treated with risperidone had significantly lower levels of the early lesion burden than the STAT5 $a^{+/+}$mice treated with risperidone $(p=0$. 005 ; Fig. 4c), and further, these low levels were comparable to the levels in the vehicle control STAT5 $a^{-1-}$ mice ( $p=0.995$; Fig. $4 c)$. Taken together, these results demonstrate that STAT5 activity is responsible for evading the apoptosis anticancer barrier in early lesions and for instigating early lesion progression.
Prophylactic treatment with an inhibitor of the JAK/STAT signaling pathway restores the apoptosis anticancer barrier in early lesions and decelerates their progression Many older women on hyperprolactinemia-inducing antipsychotics may have already accumulated early lesions and subsequently may be at increased risk of breast cancer due to family history, older age, or other reasons. Our aforementioned findings suggest that these antipsychotics likely also stimulate the progression of the early lesions in these high-risk women. For these women, it may be advisable to switch to another antipsychotic that does not cause hyperprolactinemia; however, switching to another drug is often difficult for fear of relapse and/or withdrawal effects. Consequently, it is important to identify effective breast cancer preventive strategies in high-risk women who need to take these types of antipsychotics. There are currently only a few US Food and Drug Administrtion (FDA)-approved drugs for breast cancer chemoprevention, all of which antagonize estrogen signaling [62]. As these drugs require 5 years of continuous treatment to lower breast cancer risk by $50 \%$, do not prevent estrogen receptor (ER)-negative cancer, and can have significant side effects, they are not widely used for prevention [62]. 
However, we have previously reported that short-term suppression of either pSTAT5 or JAK1/2 activity can restore the apoptosis anticancer barrier and reduce mammary tumor risk in mouse models [11]. Ruxolitinib is an FDA-approved small molecule inhibitor of JAK1/2 for the treatment of myelofibrosis and polycythemia vera; it has minimal significant side effects following short-term use in healthy individuals [63-66]. Therefore, we asked whether short-term ruxolitinib treatment could prevent mammary tumors in early lesion-bearing mice on risperidone. Here, ruxolitinib-supplemented or control chow was fed to risperidone-treated mice bearing early lesions initiated by RCAS-caErbB2. After 2 weeks of treatment, serum PRL levels in both cohorts remained elevated, as expected ( $p=0.98$; Additional file 7 : Figure S7A); however, ruxolitinib significantly lowered the percentages of pSTAT5+ cells in early lesions ( $p$ $<0.0001$; Additional file 7: Figure S7B), indicating that risperidone-induced activation of STAT5 depends on JAK1/2 activity. Ruxolitinib did not affect precancerous cell proliferation based on Ki67 $(p=0.629$; Fig. $5 \mathrm{a})$, as expected from non-detectable impact on precancerous cell proliferation by risperidone; however, mice fed with ruxolitinib chow had restored apoptosis in early lesions as measured by CC3 and TUNEL ( $p=0.006$ and 0.0357 , respectively; Fig. 5b-c), reaching/surpassing the levels detected in early lesions in mice not treated with any antipsychotic (Fig. 2c-d). Importantly, these mice had a much lower early lesion burden than the mice on the control chow $(p=0.024$; Fig. $5 \mathrm{~d})$. Furthermore, we investigated whether ruxolitinib could prevent/ delay tumor appearance. Here, we injected MMTVtva mice $(\mathrm{n}=14), 10$ weeks of age, with RCASHrasQ61L virus. Five days later, we randomized the mice into two groups for risperidone water plus ruxolitinib-supplemented chow or for risperidone water plus control chow. While the control-chow-
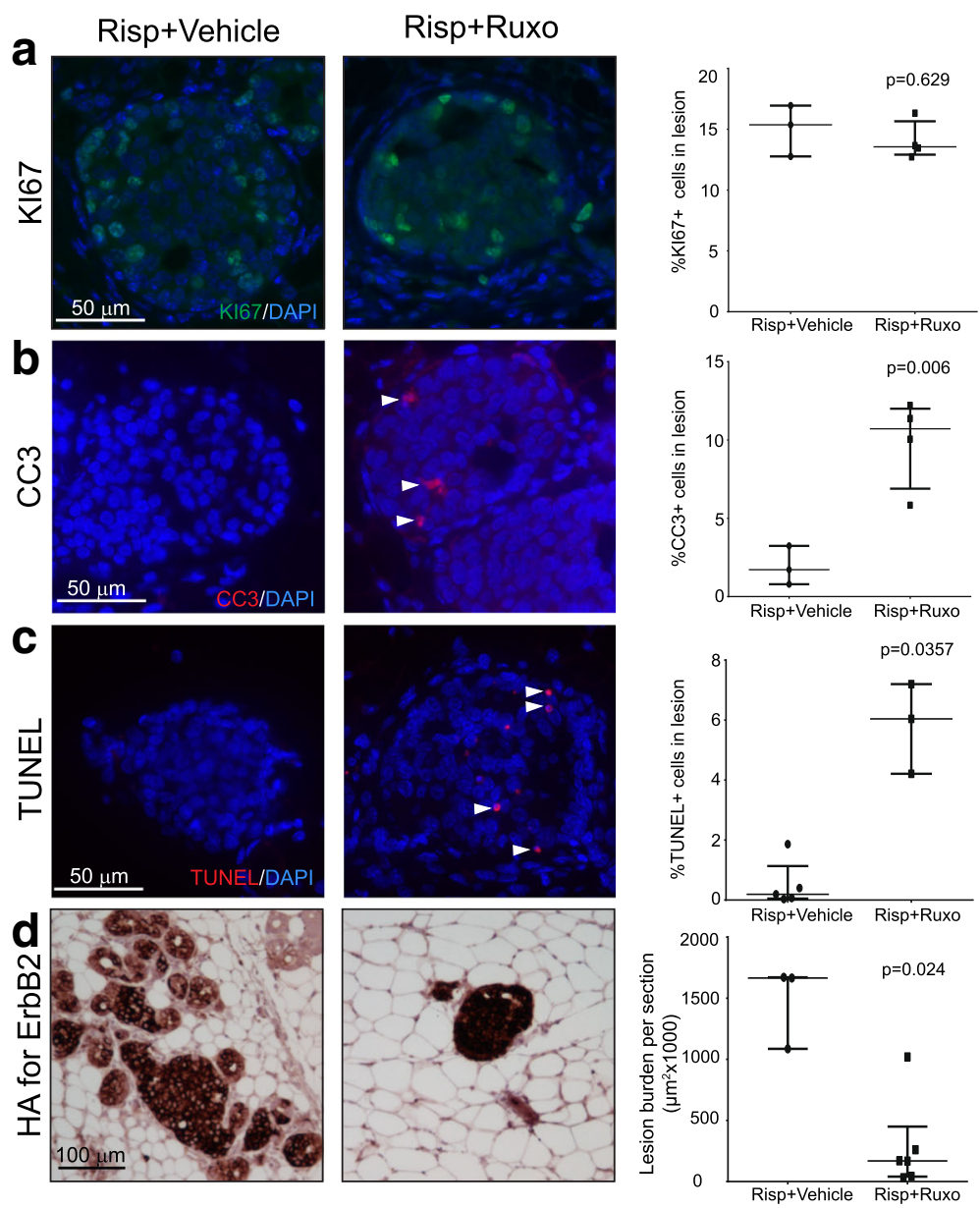

Fig. 5 Ruxolitinib (Ruxo) treatment restore the apoptosis anticancer barrier and blocks early lesion expansion. a Immunofluorescence staining for Ki67 and the resulting dot plot. $\mathbf{b}$ and $\mathbf{c}$ Immunofluorescence staining for cleaved caspase 3 (b) and TUNEL assay (c) with the accompanying dot plots. $\mathbf{d}$ Immunohistochemistry analysis and the accompanying dot plot for the HA tag on RCAS-caErbB2 provirus. The $p$ values were determined by the Mann-Whitney test. Each dot in these plots represents one mouse. Risp, risperidone 
treated mice on risperidone developed tumors with a median latency of 9 days, the ruxolitinib-chow cohort on risperidone developed tumors with an extended median latency of 13 days $(p=0.008$; Additional file 7: Figure S7C). These data further confirmed the importance of PRL-stimulated JAK-STAT5 signaling in lowering the apoptosis anticancer barrier and in increasing early lesion burden and progression in mice on risperidone. Taken together, short-term treatment with ruxolitinib restores apoptosis in early lesions, reduces early lesion burden, and lowers mammary tumor risk in mice on hyperprolactinemiainducing antipsychotics; therefore, these data suggest that prophylactic treatment with ruxolitinib may lower breast cancer risk in high-risk women who are on these antipsychotics.

\section{Discussion}

Using three different mouse models of breast cancer, we demonstrated that hyperprolactinemia-inducing antipsychotics cause preexisting premalignant lesions in the mammary gland to lower the apoptosis anticancer barrier and to accelerate the progression to cancer. We further demonstrated that this cancerinstigating effect is via upregulation of the STAT5 signaling pathway, which is known to transactivate antiapoptosis genes including $B c l-x L$. Antipsychotics and other pharmaceuticals of similar classes that do not induce hyperprolactinemia do not activate the STAT5 signaling pathway, nor do they lower the apoptosis barrier; consequently, they do not confer a tumorigenic advantage to precancerous cells. These preclinical findings have important clinical implications. For women who already have preexisting early lesions such as atypical ductal hyperplasia $(\mathrm{ADH})$ or ductal carcinoma in situ (DCIS), taking hyperprolactinemiainducing antipsychotics for a long term may increase breast cancer risk and should be carefully considered for psychiatric benefits versus breast cancer risk. Unless necessary, perhaps non-hyperprolactinemiainducing alternatives could be considered as a firstline therapy and should be suggested as a possible substitute in high-risk women who are currently taking hyperprolactinemia-inducing antipsychotics.

Our data also offer an explanation for the contradictory findings in epidemiological studies of association between antipsychotic use and breast cancer risk [19, 24, $27,28,30,31,67]$. First, many of these studies did not differentiate between hyperprolactinemia-inducing antipsychotics and other drugs that do not raise serum PRL levels significantly. Second, and perhaps as equally important, PRL-mediated JAK2-STAT5 signaling has a dichotomous effect on mammary cells. Elevated JAK2STAT5 signaling can weaken the apoptosis anticancer barrier in precancerous lesions that have already formed in the otherwise normal breast epithelia and thus may potentially increase breast cancer risk [11]. The same signaling pathway can cause the mammary cells to undergo differentiation potentially leading to lower cell proliferation rates and thus may reduce the chance of gaining mutations and consequently breast cancer risk [68]. This dichotomous function of JAK2-STAT5 has been reported by us as a major mechanism to explain the dichotomous effects of pregnancy on breast cancer risk - while an early-age pregnancy protects against breast cancer, a late-age pregnancy increases breast cancer risk [11]. At a young age, the breast epithelia are unlikely to have accumulated mutated cells. Pregnancy at this time induces these normal cells to differentiate. As a result, they become less proliferative and less likely to suffer mutations, and cancer risk is reduced. In contrast, at an older age, mutated cells are more likely to have accumulated. Pregnancy at this time with elevated JAK2-STAT5 activity can cause these precancerous cells to evade the apoptosis anticancer barrier and to evolve into cancer at accelerated speeds. The same may hold true in patients on antipsychotics. While hyperprolactinemia-inducing antipsychotics may increase breast cancer in women who have already gained precancerous cells, they may even lower the cancer risk in women who have not yet accumulated early lesions, such as younger women without any family history of early breast cancer. Consequently, it may not be a surprise that these more general epidemiological studies have generated inconclusive data on antipsychotics and breast cancer risk. Our findings suggest that it is now important to specifically study the association between hyperprolactinemia-inducing antipsychotics and the breast cancer risk in women with preexisting precancerous early lesions.

In order to avoid relapse and withdrawal effects, most patients on antipsychotics receive the same antipsychotic medication for extended periods of time and are sometimes unable to switch to other types of medication, such as those that do not cause hyperprolactinemia. Therefore, if carefully designed epidemiological studies confirm our animal model findings in the human population, prophylactic treatment will then be needed to alleviate the increased breast cancer risk caused by antipsychotics so that patients can still receive the psychiatric care that they need without elevated breast cancer incidence. Currently available chemoprevention drugs require 5 years of continuous treatment, cannot prevent ER-negative tumors that are more difficult to treat, and can have significant side effects [69]. These drawbacks discourage women who are as yet cancer-free from using them. The FDA-approved JAK1/2 inhibitor ruxolitinib has few adverse side effects when used short- 
term [66, 70, 71]. Even used for only 2 weeks, ruxolitinib was previously found to restore apoptosis in early lesions and to decelerate early lesion progression [11]. In the current study, prophylactic treatment with ruxolitinib induced apoptosis in early lesions and reduced early lesion burden in risperidone-treated mice. This finding predicts that in women with risk factors suggesting the presence of early lesions (ADH and DCIS), short-term or intermittent treatment with ruxolitinib may also reduce precancerous lesion burden and thus negate the elevated breast cancer risk induced by hyperprolactinemiainducing antipsychotics. Since JAK2-STAT5 signaling plays a crucial role in stimulating early lesion progression even in the absence of antipsychotics [7], such prophylactic treatment may reduce breast cancer risk both associated with and independent of antipsychotic use. An additional benefit of our chemoprevention modality is that it also has the potential to prevent both ER+ and ER- breast cancers, in contrast to current cancer prevention therapies that antagonize estrogen signaling and prevent ER+ breast cancer only [62]. Therefore, this chemoprevention strategy may be highly valuable for women with high breast cancer risk whether they are on antipsychotics or not.

\section{Conclusions}

In conclusion, this mouse model study demonstrates that hyperprolactinemia-inducing antipsychotics activate JAK-STAT5 signaling to lower the apoptosis anticancer barrier in preexisting precancerous early lesions and to incite their progression to cancer. To our knowledge, this is the first study that decisively links antipsychotic use to increased breast cancer risk while also providing a mechanistic insight. Our work also suggests short-term or intermittent ruxolitinib treatment as a potentially effective and more acceptable approach for preventing breast cancer risk in women on these antipsychotics.

\section{Additional files}

Additional file 1: Figure S1. Risperidone treatment does not affect tumor histopathology or lung metastatic potential. (A) H\&E staining of tumor sections. (B) qPCR analysis of lung metastasis and the resulting dot plot analyzed using the Mann-Whitney test. Each dot in this plot represents one mouse. (Al $4884 \mathrm{~kb}$ )

Additional file 2: Figure S2. Risperidone treatment accelerates early lesion development of MMTV-Wnt1 transgenic mice. (A) Carmine whole mount staining of mammary glands from MMTV-Wnt1 transgenic mice. (B) H\&E staining of mammary gland sections of MMTV-Wnt1 mice. (C) PSTAT5 immunohistochemical staining of mammary gland sections of MMTV-Wnt1 mice. (Al $22593 \mathrm{~kb}$ )

Additional file 3: Figure S3. Pimozide increases serum prolactin levels, PSTAT5 in early lesions, and $\beta$-casein, while aripiprazole does not impact pSTAT5. (A) Serum prolactin levels. (B) PSTAT5+ cells determined by immunohistochemistry analysis. (C) Immunohistochemistry analysis of $\beta$-casein. (D) PSTAT5+ cells determined by immunohistochemistry analysis. The $p$ values were determined using the Mann-Whitney test. Each dot in these plots represents one mouse. (Al $6764 \mathrm{~kb}$ )
Additional file 4: Figure S4. Pimozide accelerates the development of early lesions initiated by RCAS-caErbB2 while lowering the anticancer barrier of apoptosis. (A) Immunohistochemical staining for the HA tag on the RCAS-ErbB2 provirus with the corresponding dot plot. (B) Immunofluorescence staining for Ki67 with the accompanying dot plot. (C and D) Immunofluorescence staining for cleaved caspase 3 (C) and TUNEL assay (D) with the accompanying dot plots. The Mann-Whitney test was used to determine the $p$ values. Each dot in these plots represents one mouse. (Al $15221 \mathrm{~kb}$ )

Additional file 5: Figure S5. Effects of aripiprazole and clomipramine on biomarkers and lesion burden. (A) Serum prolactin levels of mice in the aripiprazole study. (B) Lesion burden determined by

immunohistochemical staining for the HA tag on RCAS-caErbB2. (C) Ki67 + cells determined by immunofluorescence staining. (D) TUNEL+ cells. (E) Serum prolactin levels of mice in the clomipramine study. (F) Lesion burden determined by immunohistochemical staining for the HA tag on RCAS-caErbB2. The $p$ values were determined using the Mann-Whitney test. Each dot in these plots represents one mouse. (Al $713 \mathrm{~kb}$ )

Additional file 6: Figure S6. Effects of genetic ablation of STAT5a on downstream factors of STAT5. Immunohistochemistry analysis of $\beta$-casein in caErbB2 early lesions. (Al $4570 \mathrm{~kb}$ )

Additional file 7: Figure S7. Effects of ruxolitinib on PSTAT5 and tumor latency. (A) Serum prolactin levels of mice. (B) Immunohistochemistry analysis and the accompanying dot plot for PSTAT5+ cells. The $p$ values were determined using the Mann-Whitney test. Each dot in this plot represents one mouse. (C) Kaplan-Meier tumor-free survival curve of mice infected by RCAS-HRasQ61L. The $p$ value was determined by generalized Gehan-Wilcoxon test with Rho $=1$. (Al $6247 \mathrm{~kb}$ )

\section{Acknowledgements}

We thank Weiyu Jiang and Ashaki Nehisi for technical assistance and Suzanne Fuqua, Phung Thuy, Mothaffar Rimawi, Xiang Zhang, Daniel Medina, Jeffrey Rosen, Michael Lewis, and Gary Chamness for stimulating discussions and/or critical review of this manuscript.

\section{Funding}

This work was supported in part by funds from NIH R01CA205594 (to YL) and P50CA186784 (YL); from DOD CDMRP BC123368 (to YL); and from Susan G. Komen for the Cure PDF15330612 (YL); and by the resources from the Dan L. Duncan Cancer Center (P30CA125123). AJ was supported by T32GM088129. SMH was supported by the CPRIT Training Program (RP101499) and by NIH training award T32AG000183.

\section{Availability of data and materials}

All data generated or analyzed during this study are included in this published article and its supplementary information files.

\section{Authors' contributions}

AJ performed the majority of the experiments and statistical analyses. WB oversaw much of the experimental planning, ideas, and data analyses. SH participated in the IHC/IF staining for the risperidone early lesion section. SG participated in IHC/IF for the ruxolitinib studies. LC performed the lung metastasis analysis. LX participated in tumor procurement and IHC. LQ performed the initial experiments in this study. CN determined tumor histopathology. HS confirmed all statistical analyses. KP constructed RCASHRasQ61L. JK performed $\beta$-casein immunostaining and participated in STAT5 knockout and ruxolitinib tumor studies. JN provided clinical input. YL is the principal investigator for this project. All authors read and approved the final manuscript.

\section{Ethics approval}

All animals were handled according to the animal protocol approved by the Institutional Animal Care and Use Committee (IACUC) at Baylor College of Medicine.

\section{Competing interests}

Dr. Li receives the ruxolitinib and research support from Incyte Corp. The authors declare that they have no other competing interests 


\section{Publisher's Note}

Springer Nature remains neutral with regard to jurisdictional claims in published maps and institutional affiliations.

\begin{abstract}
Author details
${ }^{1}$ Translational Biology and Molecular Medicine, Baylor College of Medicine, Houston, TX 77030, USA. ${ }^{2}$ Lester and Sue Smith Breast Center, Baylor College of Medicine, Baylor College of Medicine, Houston, TX 77030, USA. ${ }^{3}$ Dan L. Duncan Cancer Center, Baylor College of Medicine, Houston, TX 77030, USA. ${ }^{4}$ Molecular and Cellular Biology, Baylor College of Medicine, Houston, TX 77030, USA. ${ }^{5}$ SMART PREP Program, Baylor College of Medicine, One Baylor Plaza, Houston, TX 77030, USA. ${ }^{6}$ Institut Curie, PSL Research University, CNRS, UMR3664, Equipe Labellisée Ligue contre le Cancer, F-75005 Paris, France. ${ }^{7}$ Sorbonne Universités, UPMC Université Paris 06, CNRS, UMR3664, F-75005 Paris, France. ${ }^{8}$ Molecular Virology and Microbiology, Baylor College of Medicine, One Baylor Plaza, Houston, TX 77030, USA.
\end{abstract}

Received: 30 November 2017 Accepted: 11 April 2018

Published online: 19 May 2018

\section{References}

1. Lindsley CW. The top prescription drugs of 2011 in the United States: antipsychotics and antidepressants once again lead CNS therapeutics. ACS Chem Neurosci. 2012;3(8):630-1.

2. Peuskens J, Pani L, Detraux J, De Hert M. The effects of novel and newly approved antipsychotics on serum prolactin levels: a comprehensive review. CNS drugs. 2014;28(5):421-53.

3. Montgomery J, Winterbottom E, Jessani M, Kohegyi E, Fulmer J, Seamonds B, Josiassen RC. Prevalence of hyperprolactinemia in schizophrenia: association with typical and atypical antipsychotic treatment. J Clin Psychiatry. 2004;65(11):1491-8.

4. Suliman AM, Smith TP, Gibney J, McKenna TJ. Frequent misdiagnosis and mismanagement of hyperprolactinemic patients before the introduction of macroprolactin screening: application of a new strict laboratory definition of macroprolactinemia. Clin Chem. 2003:49(9):1504-9.

5. Meltzer HY, Fang VS. The effect of neuroleptics on serum prolactin in schizophrenic patients. Arch Gen Psychiatry. 1976;33(3):279-86.

6. Haddad PM, Wieck A. Antipsychotic-induced hyperprolactinaemia: mechanisms, clinical features and management. Drugs. 2004;64(20):2291-314.

7. Haricharan S, Li Y. STAT signaling in mammary gland differentiation, cell survival and tumorigenesis. Mol Cell Endocrinol. 2014;382(1):560-9.

8. lavnilovitch E, Groner B, Barash I. Overexpression and forced activation of stat5 in mammary gland of transgenic mice promotes cellular proliferation, enhances differentiation, and delays postlactational apoptosis. Mol Cancer Res. 2002;1(1):32-47.

9. Dong J, Tong T, Reynado AM, Rosen JM, Huang S, Li Y. Genetic manipulation of individual somatic mammary cells in vivo reveals a master role of STAT5a in inducing alveolar fate commitment and lactogenesis even in the absence of ovarian hormones. Dev Biol. 2010;346(2):196-203.

10. Torre DL, Falorni A. Pharmacological causes of hyperprolactinemia. Ther Clin Risk Manag. 2007;3(5):929-51

11. Haricharan S, Dong J, Hein S, Reddy JP, Du Z, Toneff M, Holloway K, Hilsenbeck SG, Huang S, Atkinson R, et al. Mechanism and preclinical prevention of increased breast cancer risk caused by pregnancy. elife. 2013;2(0):e00996.

12. Peck AR, Witkiewicz AK, Liu C, Stringer GA, Klimowicz AC, Pequignot $E$, Freydin B, Tran TH, Yang N, Rosenberg AL, et al. Loss of nuclear localized and tyrosine phosphorylated Stat5 in breast cancer predicts poor clinical outcome and increased risk of antiestrogen therapy failure. J Clin Oncol. 2011;29(18):2448-58.

13. Nevalainen MT, Xie J, Bubendorf L, Wagner KU, Rui H. Basal activation of transcription factor signal transducer and activator of transcription (Stat5) in nonpregnant mouse and human breast epithelium. Mol Endocrinol. 2002; 16(5):1108-24

14. Cotarla I, Ren S, Zhang Y, Gehan E, Singh B, Furth PA. Stat5a is tyrosine phosphorylated and nuclear localized in a high proportion of human breast cancers. Int J Cancer. 2004:108(5):665-71.

15. Walker SR, Xiang M, Frank DA. Distinct roles of STAT3 and STAT5 in the pathogenesis and targeted therapy of breast cancer. Mol Cell Endocrinol. 2014;382(1):616-21.
16. Shi A, Dong J, Hilsenbeck S, Bi L, Zhang H, Li Y. The status of STAT3 and STAT5 in human breast atypical ductal hyperplasia. PLoS One. 2015;10(7):e0132214.

17. Thomas SJ, Snowden JA, Zeidler MP, Danson SJ. The role of JAK/STAT signalling in the pathogenesis, prognosis and treatment of solid tumours. $\mathrm{Br}$ J Cancer. 2015;113(3):365-71.

18. Gilbert PL, Harris MJ, McAdams LA, Jeste DV. Neuroleptic withdrawal in schizophrenic patients. A review of the literature. Arch Gen Psychiatry. 1995;52(3):173-88.

19. De Hert M, Peuskens J, Sabbe T, Mitchell AJ, Stubbs B, Neven P, Wildiers H, Detraux J. Relationship between prolactin, breast cancer risk, and antipsychotics in patients with schizophrenia: a critical review. Acta Psychiatr Scand. 2016:133(1):5-22.

20. Mitchell AJ, Pereira IE, Yadegarfar M, Pepereke S, Mugadza V, Stubbs B. Breast cancer screening in women with mental illness: comparative metaanalysis of mammography uptake. Br J Psychiatry. 2014;205(6):428-35.

21. Kisely S, Crowe E, Lawrence D. Cancer-related mortality in people with mental illness. JAMA Psychiat. 2013;70(2):209-17.

22. Smith DJ, Langan J, McLean G, Guthrie B, Mercer SW. Schizophrenia is associated with excess multiple physical-health comorbidities but low levels of recorded cardiovascular disease in primary care: cross-sectional study. BMJ Open. 2013;3(4):e002808

23. Carney CP, Jones L, Woolson RF. Medical comorbidity in women and men with schizophrenia: a population-based controlled study. J Gen Intern Med. 2006;21(11):1133-7.

24. Goode DJ, Corbett WT, Schey HM, Suh SH, Woodie B, Morris DL, Morrisey L. Breast cancer in hospitalized psychiatric patients. Am J Psychiatry. 1981; 138(6):804-6.

25. Kanhouwa S, Gowdy JM, Solomon JD. Phenothiazines and breast cancer. J Natl Med Assoc. 1984;76(8):785-8.

26. Overall JE. Prior psychiatric treatment and the development of breast cancer. Arch Gen Psychiatry. 1978:35(7):898-9.

27. Ettigi P, Lal S, Friesen HG. Prolactin, phenothiazines, admission to mental hospital, and carcinoma of the breast. Lancet. 1973;2(7823):266-7.

28. Wagner S, Mantel N. Breast cancer at a psychiatric hospital before and after the introduction of neuroleptic agents. Cancer Res. 1978;38(9):2703-8.

29. Seeman MV. Secondary effects of antipsychotics: women at greater risk than men. Schizophr Bull. 2009:35(5):937-48.

30. Rahman T, Clevenger CV, Kaklamani V, Lauriello J, Campbell A, Malwitz K, Kirkland RS. Antipsychotic treatment in breast cancer patients. Am J Psychiatry. 2014;171(6):616-21.

31. Froes Brandao D, Strasser-Weippl K, Goss PE. Prolactin and breast cancer: the need to avoid undertreatment of serious psychiatric illnesses in breast cancer patients: a review. Cancer. 2016;122(2):184-8.

32. Halbreich $U$, Shen J, Panaro V. Are chronic psychiatric patients at increased risk for developing breast cancer? Am J Psychiatry. 1996;153(4):559-60.

33. Wang PS, Walker AM, Tsuang MT, Orav EJ, Glynn RJ, Levin R, Avorn J. Dopamine antagonists and the development of breast cancer. Arch Gen Psychiatry. 2002:59(12):1147-54

34. Du Z, Podsypanina K, Huang S, McGrath A, Toneff MJ, Bogoslovskaia E, Zhang X, Moraes RC, Fluck M, Allred DC, et al. Introduction of oncogenes into mammary glands in vivo with an avian retroviral vector initiates and promotes carcinogenesis in mouse models. Proc Natl Acad Sci U S A. 2006; 103(46):17396-401.

35. Liu X, Robinson GW, Wagner KU, Garrett L, Wynshaw-Boris A, Hennighausen L. Stat5a is mandatory for adult mammary gland development and lactogenesis. Genes Dev. 1997;11(2):179-86.

36. Reddy JP, Li Y. The RCAS-TVA system for introduction of oncogenes into selected somatic mammary epithelial cells in vivo. J Mammary Gland Biol Neoplasia. 2009;14(4):405-9.

37. Bachmanov AA, Reed DR, Beauchamp GK, Tordoff MG. Food intake, water intake, and drinking spout side preference of 28 mouse strains. Behav Genet. 2002;32(6):435-43

38. Hein SM, Haricharan S, Johnston AN, Toneff MJ, Reddy JP, Dong J, Bu W, Li Y. Luminal epithelial cells within the mammary gland can produce basal cells upon oncogenic stress. Oncogene. 2016;35(11):1461-7.

39. Toneff MJ, Du Z, Dong J, Huang J, Sinai P, Forman J, Hilsenbeck S, Schiff R, Huang S, Li Y. Somatic expression of PyMT or activated ErbB2 induces estrogen-independent mammary tumorigenesis. Neoplasia. 2010;12(9):718-26.

40. Holloway KR, Sinha VC, Bu W, Toneff M, Dong J, Peng Y, Li Y. Targeting oncogenes into a defined subset of mammary cells demonstrates that the 
initiating oncogenic mutation defines the resulting tumor phenotype. Int Biol Sci. 2016;12(4):381-8.

41. Holloway KR, Sinha VC, Toneff MJ, Bu W, Hilsenbeck SG, Li Y. Krt6a-positive mammary epithelial progenitors are not at increased vulnerability to tumorigenesis initiated by ErbB2. PLoS One. 2015;10(1):e0117239.

42. Sinha VC, Qin L, Li Y. A p53/ARF-dependent anticancer barrier activates senescence and blocks tumorigenesis without impacting apoptosis. Mol Cancer Res. 2015;13(2):231-8.

43. Li Y, Ferris A, Lewis BC, Orsulic S, Williams BO, Holland EC, Hughes SH. The RCAS/TVA somatic gene transfer method in modeling human cancer. In: Green JE, Ried T, editors. Genetically-engineered mice for cancer research: design, analysis, pathways, validation and pre-clinical testing: Springer; 2011. p. 83-111.

44. Reddy JP, Peddibhotla S, Bu W, Zhao J, Haricharan S, Du YC, Podsypanina K, Rosen JM, Donehower LA, Li Y. Defining the ATM-mediated barrier to tumorigenesis in somatic mammary cells following ErbB2 activation. Proc Natl Acad Sci U S A. 2010;107(8):3728-33.

45. Slamon DJ, Godolphin W, Jones LA, Holt JA, Wong SG, Keith DE, Levin WJ, Stuart SG, Udove J, Ullrich A, et al. Studies of the HER-2/neu proto-oncogene in human breast and ovarian cancer. Science. 1989;244(4905):707-12.

46. Zheng ZY, Tian L, Bu W, Fan C, Gao X, Wang H, Liao YH, Li Y, Lewis MT, Edwards D, et al. Wild-type N-Ras, overexpressed in basal-like breast cancer, promotes tumor formation by inducing $\mathrm{IL}-8$ secretion via JAK2 activation. Cell Rep. 2015;12(3):511-24

47. Hoadley KA, Weigman VJ, Fan C, Sawyer LR, He X, Troester MA, Sartor CI, Rieger-House T, Bernard PS, Carey LA, et al. EGFR associated expression profiles vary with breast tumor subtype. BMC Genomics. 2007;8:258.

48. Cancer Genome Atlas Network. Comprehensive molecular portraits of human breast tumours. Nature. 2012;490(7418):61-70.

49. Cerami E, Gao J, Dogrusoz U, Gross BE, Sumer SO, Aksoy BA, Jacobsen A, Byrne CJ, Heuer ML, Larsson E, et al. The cBio cancer genomics portal: an open platform for exploring multidimensional cancer genomics data. Cancer Dis. 2012;2(5):401-4.

50. Tsukamoto AS, Grosschedl R, Guzman RC, Parslow T, Varmus HE. Expression of the int-1 gene in transgenic mice is associated with mammary gland hyperplasia and adenocarcinomas in male and female mice. Cell. 1988;55(4):619-25.

51. Herschkowitz JI, Simin K, Weigman VJ, Mikaelian I, Usary J, Hu Z, Rasmussen KE, Jones LP, Assefnia S, Chandrasekharan S, et al. Identification of conserved gene expression features between murine mammary carcinoma models and human breast tumors. Genome Biol. 2007:8(5):R76.

52. Zhang X, Podsypanina K, Huang S, Mohsin SK, Chamness GC, Hatsell S, Cowin P, Schiff R, Li Y. Estrogen receptor positivity in mammary tumors of Wnt-1 transgenic mice is influenced by collaborating oncogenic mutations. Oncogene. 2005;24(26):4220-31.

53. Li Y, Welm B, Podsypanina K, Huang S, Chamorro M, Zhang X, Rowlands T, Egeblad M, Cowin P, Werb Z, et al. Evidence that transgenes encoding components of the Wnt signaling pathway preferentially induce mammary cancers from progenitor cells. Proc Natl Acad Sci U S A. 2003;100(26):15853-8.

54. Hanahan D, Weinberg RA. Hallmarks of cancer: the next generation. Cell. 2011;144(5):646-74.

55. Tomlinson IP, Bodmer WF. Failure of programmed cell death and differentiation as causes of tumors: some simple mathematical models. Proc Natl Acad Sci U S A. 1995;92(24):11130-4.

56. Walton KD, Wagner KU, Rucker EB 3rd, Shillingford JM, Miyoshi K, Hennighausen L. Conditional deletion of the bcl-x gene from mouse mammary epithelium results in accelerated apoptosis during involution but does not compromise cell function during lactation. Mech Dev. 2001;109(2):281-93.

57. Rosen JM, Wyszomierski SL, Hadsell D. Regulation of milk protein gene expression. Annu Rev Nutr. 1999;19(1):407-36.

58. Nelson EA, Walker SR, Weisberg E, Bar-Natan M, Barrett R, Gashin LB, Terrell S, Klitgaard JL, Santo L, Addorio MR, et al. The STAT5 inhibitor pimozide decreases survival of chronic myelogenous leukemia cells resistant to kinase inhibitors. Blood. 2011;117(12):3421-9.

59. Nelson EA, Walker SR, Xiang M, Weisberg E, Bar-Natan M, Barrett R, Liu S, Kharbanda S, Christie AL, Nicolais M, et al. The STAT5 inhibitor pimozide displays efficacy in models of acute myelogenous leukemia driven by FLT3 mutations. Genes Cancer. 2012;3(7-8):503-11.

60. Neilson LM, Zhu J, Xie J, Malabarba MG, Sakamoto K, Wagner KU, Kirken RA, Rui H. Coactivation of janus tyrosine kinase (Jak)1 positively modulates prolactin-Jak2 signaling in breast cancer: recruitment of ERK and signal transducer and activator of transcription (Stat)3 and enhancement of Akt and Stat5a/b pathways. Mol Endocrinol. 2007;21(9):2218-32.
61. Liu X, Robinson GW, Gouilleux F, Groner B, Hennighausen L. Cloning and expression of Stat5 and an additional homologue (Stat5b) involved in prolactin signal transduction in mouse mammary tissue. Proc Natl Acad Sci U S A. 1995;92(19):8831-5.

62. Brown P. Prevention: targeted therapy-anastrozole prevents breast cancer. Nat Rev Clin Oncol. 2014;11(3):127-8.

63. Ogama Y, Mineyama T, Yamamoto A, Woo M, Shimada N, Amagasaki T, Natsume K. A randomized dose-escalation study to assess the safety, tolerability, and pharmacokinetics of ruxolitinib (INC424) in healthy Japanese volunteers. Int J Hematol. 2013;97(3):351-9.

64. Shi JG, Chen X, Emm T, Scherle PA, McGee RF, Lo Y, Landman RR, McKeever EG Jr, Punwani NG, Williams W, et al. The effect of CYP3A4 inhibition or induction on the pharmacokinetics and pharmacodynamics of orally administered ruxolitinib (INCB018424 phosphate) in healthy volunteers. J Clin Pharmacol. 2012:52(6):809-18.

65. Sonbol MB, Firwana B, Zarzour A, Morad M, Rana V, Tiu RV. Comprehensive review of JAK inhibitors in myeloproliferative neoplasms. Ther Adv Hematol. 2013:4(1):15-35

66. Quintas-Cardama A, Vaddi K, Liu P, Manshouri T, Li J, Scherle PA, Caulder E, Wen $X$, Li Y, Waeltz $P$, et al. Preclinical characterization of the selective JAK1/ 2 inhibitor INCB018424: therapeutic implications for the treatment of myeloproliferative neoplasms. Blood. 2010;115(15):3109-17.

67. Reutfors J, Wingard L, Brandt L, Wang Y, Qiu H, Kieler H, Bahmanyar S. Risk of breast cancer in risperidone users: a nationwide cohort study. Schizophr Res. 2017;182:98-103.

68. Medina D. Breast cancer: the protective effect of pregnancy. Clin Cancer Res. 2004;10(1 Pt 2):380S-4S.

69. Hutchinson L. Prevention: Mapping out breast cancer chemoprevention. Nat Rev Clin Oncol. 2011;8(8):445

70. Mesa RA. Ruxolitinib, a selective JAK1 and JAK2 inhibitor for the treatment of myeloproliferative neoplasms and psoriasis. IDrug. 2010;13(6):394-403.

71. Swaim SJ. Ruxolitinib for the treatment of primary myelofibrosis. AJHP. 2014; 71(6):453-62.

\section{Ready to submit your research? Choose BMC and benefit from:}

- fast, convenient online submission

- thorough peer review by experienced researchers in your field

- rapid publication on acceptance

- support for research data, including large and complex data types

- gold Open Access which fosters wider collaboration and increased citations

- maximum visibility for your research: over $100 \mathrm{M}$ website views per year

At BMC, research is always in progress.

Learn more biomedcentral.com/submissions 